559

POLYAMINE (PA) METABOLISM IN CYSTIC FIBROSIS (CF) M.G. Rosenblum, R.C. Beckerman, L.M. Taussig, B.G.M.
Durie, B. H. Bowman, D. Barnett, D.H. Russell. Univ. of Arizona Health Sciences Center, Tucson, AZ. and University of Texas Medical Branch, Galveston, TX.

Prior studies have shown that PA levels are elevated in blood components of $\mathrm{CF}$ homozygotes. We have studied urinary PA levels and ${ }^{14} \mathrm{C}$ spermidine metabolism in controls and $\mathrm{CF}$ patients. The urinary PA levels in $7 \mathrm{CF}$ homozygotes were 2-10 fold higher than in 8 heterozygotes and 6 normals $(p<0.0001)$. No statistically ignificant differences were found between heterozygotes and controls. The ${ }^{14} \mathrm{C}$ spermidine plasma decay curves in two $\mathrm{CF}$ patients with severe clinical disease (NIH Score $<50$ ) were not significantly different from normal. However, urinary excertion ff the ${ }^{14} \mathrm{C}$ radiolabel by the $2 \mathrm{CF}$ patients was only about $10 \%$ as compared to $60-76 \%$ excreted by normals after 72 hours. Urine roup of $12 \mathrm{CF}$. ( trated statistically significant lower levels of putrescine ( $p$ $0.05)$ and significantly higher levels of spermine $(p<0.01)$ than those with scores $>70(N=8)$. These data show that although lasma decay curves for ${ }^{14} \mathrm{C}$ spermidine are similar to normals, the urinary excretion pattern suggests sequestration in $\mathrm{CF}$ patients with severe clinical disease. Further, polyamine levels are elevated in the urine of CF homozygotes and appear to corre 1 ate well with the patient's clinical status.

supported by USPHS Grants CA-14783 and CA-17094 from the vational Cancer Institute (D.H.R.). R.B. is an ALA Fellow.

560 STUDIES OF H-Y ANTIGEN IN A $46, X Y_{\text {D- }}$ PHENOTYPIC FEMAIE WITH TURNER STIGMATA AND UNDIFFERENTIATED GONADS. ROn Rosenfeld, Luigi Luzzatti, Raymond Hintz, Orlando J Miller, Gloria Koo, Stephen Wachtel; Stanford University Dept of Peds, Stanford; Depts. Hum. Gen/Dev \& OB/GYN, College of Physicians \& Surgeons, NYC; Mem. Sloan-Kettering Cancer Center, NYC. $\mathrm{H}-\mathrm{Y}$ antigen is believed to be the product of testis-determinin gene(s) on the $\mathrm{Y}$ chromosome. A case of $46, \mathrm{XY}$ - phenotypic female provided an opportunity to evaluate both sexual and somatic deter minants on the $\mathrm{Y}$ chromosome. At birth, the infant had lymphedem of the extremities, increased nuchal skin folds and normal female external genitalia. $Q$ and $C$ banding of peripheral leukocytes demonstrated a 46,XYP- karyotype. Laparotomy demonstrated bilateral $1.5 \mathrm{~cm}$ gonads with normal uterus and tubes. Gonadal sections revealed fibrous stroma with focal aggregations of undifferentiated cells arranged in cords or clusters. At 8 years she is a phenotypic female with height in the 25 th \%, multiple stigmata of Turne Syndrome and elevated gonadotropins. H-Y phenotype assignment is based on ability of test cells to adsorb $\mathrm{H}-\mathrm{Y}$ antibodies from mous $\mathrm{H}-\mathrm{Y}$ antisera, which are then reacted with mouse sperm. Skin fibro blasts of the patient failed to adsorb $\mathrm{H}-\mathrm{Y}$ antibodies; her peripheral leukocytes adsorbed considerably less than her father's. She was thus typed $\mathrm{H}-\mathrm{Y}^{ \pm}$, a phenotype consistent with a deletion model in which a majority of $\mathrm{H}-\mathrm{Y}$ gene copies has been lost. Demonstration of the structural deletion of the $Y$ chromosome support the hypothesis that loci exist on the short arm of the $Y$ which determine $\mathrm{H}-\mathrm{Y}$ antigen, testicular differentiation of the primit gonad and suppression of somatic stigmata of Turner Syndrome.
561 ISOELECTRIC FOCUSING OF $\alpha$-L-FUCOSIDASE FROM CYSTIC FIBROSIS AND CONTROL SKIN FIBROBLASTS. Thomas F. Scanlin and Mary Catherine Glick. (Spon. by Stanto

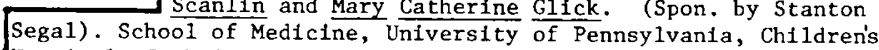
Hospital of Philadelphia, Department of Pediatrics, Philadelphia. $\alpha$-L-Fucosidase activity is elevated in cystic fibrosis (CF) skin fibroblasts while nine other acid hydrolases including neuraminidase have activities similar to those in the control fibroblasts (Biochem. Biophys. Res. Commun. 79,869,1977). Extracts of skin fibroblasts from CF individuals and age, sex, and race matched controls were analyzed by isoelectric focusing on thin layer polyacrylamide gels to determine if the elevated activity of $\alpha-L$-fucosidase in the CF cells resulted from a difference in a specific 1soenzyme. Fibroblasts were seeded at a density of $3.0 \times 10^{6}$ cells $/ 150 \mathrm{~cm}^{2}$ and harvested af ter 7 days with trypsin. Cell pellets were suspended in Triton $\mathrm{X}-100$, broken in a Dounce homogenizer and centrifuged at $10,400 \mathrm{~g}$ for $20 \mathrm{~min}$. The supernatant solutions were electrofocused for $2 \mathrm{~h}$ in an LKB Multiphor apparatus both before and after treatment with Vibrio cholerae neuraminidase. Two separate ampholine gradients, $\mathrm{pH} \frac{\mathrm{cholerae}}{3.5-10 \text { and }}$ $\mathrm{pH} 4-7$, were used. The gels were cut in $2 \mathrm{~mm}$ slices and $\alpha-\mathrm{L}-$ fucosidase activity was assayed using 4-methylumbelliferyl- $\alpha-\mathrm{I}-$ fucopyranoside as substrate in citrate buffer, $\mathrm{pH} 5.8$. The $\mathrm{CF}$ and control fibroblasts had similar isoenzyme patterns under al1 of the conditions described with the exception that several CF preparations showed a predominance of the isoenzymes with higher isoelectric polnts. USPHS GM07025 and The National Foundation-March of Dimes.
562 FAIIURE OF ASCORBIC ACID (AA) THERAPY IN NEPHROPATHIC CYSTINOSIS. J.A. Schneider, J.J. Schlesselman,

pept. of Ped., Univ. of Ca., San Diego and NICIIn, Bethesda, Md. Since there is no specific therapy for cystinosis and since $A$ A ecreases the free-cystine content of cystinotic fibrohlasts Science $86: 1040,1974)$, a randomized double-hlind trial of high dose $(200 \mathrm{mg} / \mathrm{Kg} /$ day $) \mathrm{AA}$ was undertaken. An unblinded committee monitored the data every 4 months. At entry the $A A$ and $p l a c e b o$ (PL) groups were comparable in all major clinical parameters. There were 52 patient years for the $A A$ group and 50 patient years for the PI. group. Of the 11 patients who died, began chronic dialysis or were transplanted, 8 had received AA. Neither treat ment affected the WBC cystine content. Patients receiving AA had

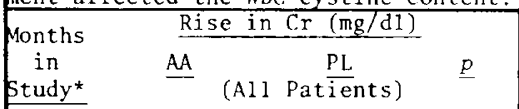
atients receiving AA had serum creatinine (Cr) serum creatinine (Cr).

2 mo $.82 \pm .29(18)^{\star \star} .42 \pm .20(19)<.3$ $16 \mathrm{mo} 1.30 \pm .43(16) .58 \pm .26(14)<.2$

20 mo $2.78 \pm .81(12) \quad .97 \pm .38(9)<.1$

(initial $\mathrm{Cr}$ of $\geq 1.0 \&<3.5)$ $90 \pm .30(11) .29 \pm .13(12)<.1$ 12 mo $\quad .90 \pm .30(11) \quad .29 \pm .13(12)<.1$ 20 mo $3.16 \pm .98(9) \quad .84 \pm .23(6) \quad<.1$ *All patients at 20 mo. are included in 16 mo. data, etc. **mean $+\operatorname{SEM}(n)$ in patients whose initial Cr vas $>1.0 \&<3.5$. $\wedge 1$ though a small benificial effect of $A A$ could not be excluded statistically. it was more likely that A A hastened the progres sion of renal failure. In view of this adverse risk-benefit ratio the study was terminiated.

\title{
563 ATypical PREsentation of tRISOMY 13 MOSAICISM
} Robin Slover, Eva Sujansky, Arthur Fobinson. Department of Biophysics and Genetics, Liniversity of Colorado Medical Center and National Jewish lospital, Lenver. We have seen two unrelated cases of Trisomy 13 mosaicism with the main presenting symptom of severe bilateral deafness and microtia respectively. To our knowledge such a presentation of Trisomy 13 mosaicism has not been reforted previously. Althourh the clinical symptoms of Trisomy 13 mosaics are variable, mental retardation and cleft palate are the most frequent findings. The first case was a 10 year old mentaliy retarded male with. severe bilateral deafness, cuplication of the ureters and a port severe bilateral deafness, cuplication of the ureters and
wine nevus. The second case presented with a riglt sidec microtia, a heart murmur and tilateral simian creases. lis psychomotor development at 6 mor.ths was normal. Chromosome analysis from the peripheral llood lymphocytes culture revealed in both cases Trisomy 13 in 15\% of cells. Our experience indicates that the diagnosis of Trisomy 13 mosaicism should be cates that the diagnosis of Trisomy 13 mosaicism should be con-
sidered in children with deafness on microtia asscciated with

sidered in children
minor malformations.

564 PEPTIDASE WITH SERINE-BORATE. Stephen $P$ Spielberg, Jean deB. Butler, and Joseph D. Schulman, Depts. of Pediatrics and Pharmacology, Johns Hopkins Univ., Baltimore, and NICHD, Bethesda. Glutathione synthetase (GSH-S) deficiency (5-oxoprolinuria) results in decreased cellular glutathione (GSH) content (10-20\% of normal), and secondary over-production of 5-oxoproline. $\gamma$-glutamyl transpeptidase (GGTP) is the primary catabolic enzyme for GSH, and inhibition of this enzyme might thus be an approach to correcting the consequences of GSH-S deficiency. L-serine inhibits fibroblost GGTP. Inhibition is markedly enhanced by sodium borate buffer, $20 \mathrm{mM}$ serine $-20 \mathrm{mM}$ borate causing $\$ 95 \%$ inhibition. Serine-borate added to Eagle's MEM produced a dose and time dependent increase in GSH content of GSH-S deficient cultured fibroblasts. GSH content was doubled at 24 hours with $40 \mathrm{mM}$ serine $-40 \mathrm{mM}$ borate. Borate alone was without effect. Conversion of ${ }^{4} \mathrm{C}$-glutamic acid to 5-oxoproline by $\mathrm{GSH}-\mathrm{S}$ deficient cells was decreased by $70 \%$ to near normal levels by 24 -hour pre-treatment with $40 \mathrm{mM}$ serine-borate. The increased cell GSH content may block overproduction of 5-oxoproline from excess $\gamma$-glutamylcysteine by feed-bock inhibiting $\gamma$-glutamylcysteine synthetase. Treatment produced no apporent toxicity; cell amino acid concentrations were unaffected other than an increase in serine and phosphoserine. The study demonstrates the possible therapeutic value of an inhibitor of a major catabolic enzyme for a substrate decreased secondary to a deficiency of its synthetic enzyme. 